\title{
Investigating the Effect of Human Resources Management (HRM) on Organizational Success Considering the Moderating Role of Work Ethics in Public Organizations of Shiraz City
}

\author{
SAEED SAYADI \\ Faculty Member of Management Department, Islamic Azad University, Kerman Branch, Kerman, Iran \\ Email: saeed.sayadi@gmail.com \\ HAMID NEMATI \\ $\mathrm{PhD}$ student of Public Administration, Department of Management Islamic Azad University, Kerman \\ branch, Kerman, Iran, \\ Email: hamid.nemati1314@gmail.com
}

\begin{abstract}
In the era of rapid changes, the role of government, citizens, and organizational is changing increasingly voluntarily or under pressure, especially public and private organizations and management systems. Following government changes, citizens do not play merely receiver role, but they play more active and participatory role. The challenges that developing countries are faced with them in management are more risk challenges than those in industrial countries. Strategic planning and management is at the core of implementing and realizing the developmental goals of the country. In Iran, the key for designing and implementing the desired development and management plans is development and management of human resources. To face with globalization challenges, managers should be effective and have high quality. This study was conducted to examine the impact of human resources management on organizational success considering the moderating role of work ethics in public organizations in Shiraz. This research is survey and causal type of study. The population of study included all 2500 staff in the city of Shiraz. Based on Morgan table, 333 of them were selected as sample of study and to ensure the return of the questionnaires, 350 subjects were selected using stratified random sampling method. Data were analyzed using PLS software and structural equations. The results showed that 6 hypotheses of study were confirmed, but the staff service compensation system had no significant impact on success of the project, selection and recruitment of staff had no significant impact success of the project considering the moderating role of work ethics, and evaluation of staff performance had no significant impact on the success of the project considering the moderating role of work ethics. Therefore, human resources management has no significant impact on organizational success considering the moderating role of work ethics in public organizations of Shiraz city.
\end{abstract}

Keywords: Human Resources Management, Organizational Success, Organizational Performance, Work Ethics.

\section{Introduction}

Today, organizations are looking for rapid growth, continuous improvement, profitability, flexibility and readiness for future to obtain privilege in their activity for survival and development. Without these qualities, it is impossible for organization to operate and compete well with competitors (Armstrong and Baron, 2003). Human resources are key elements to the success or failure of the organization. In this regard, policies, practices and human resources functions must be totally committed to corporate strategy, 
and managers and leaders of organizations should have correct understanding to its issues and be sensitive to its consequences. An organization requires using complex combination of resources to grow, survive and achieve the ultimate mission which it survival in the competition. Dynamicity and properly arrangement of the human financial resources and raw materials provides leverage for organizations to achieve their predicted objectives and goals. Among these resources, human resources are the strongest resources and the play key role in achieving the significant results and competitiveness. Therefore, organization gains sustainable competitive advantage through its staff. Competitive advantage is simply defined as "anything that gives marginal (edge) to organization relative to competitors in the market." According to Porter, unique competencies and merits in staff, including flexibility, innovation, excellence performance, high productivity and personal services to customers are methods through which staff creates a critical component in the development of the company's competitive position. In addition, there is consensus that effective management of human capital is critical in the success of the organization (Dunford et al., 2007). This issue is raised out always for officials, planners and experts in human resources in organizations of the country that performance in organizations has be improved and which factors cause that performance of staff in an organization, institution or service or manufacturing organizations to increase or decrease. Given that the intellectual capital considered among vital issues of an organization, it is expected that intellectual capital to play an essential role in the improvement of the human resources in the organization (Gollan, 2005). To understand the concept of performance evaluation, we must first understand the concept of performance. Performance refers to degree of performing the tasks that complement an employee job, and it suggests how an employee accomplishes the requirements of a job. Performance often is considered equal with spending the energy, but performance is measured based on the results of activities (Harpaz, 2010).

\section{In this regard, we refer to some of the studies similar to our study}

Hafezi and Faezi (1393) conducted a research entitled "The effect of strategic human resource management on the success of development projects". The research method is applied in terms of objective and descriptive-survey in terms of data collection. In this research, the required criteria and methods for implementing this strategy and human resource management affected by the results measurement of performance examine the impact of human resource management on the performance of development projects and the level of its development. The required data were collected using a questionnaire and the research hypotheses were tested. The results of this strategy will increase productivity and reduce turnover, which is a revolutionary strategy in development projects.

Soleimani and BaghiNasrabadi (2012) conducted a research entitled "the role of human resources management in enhancing the professional ethics". The present study is a descriptive-survey in terms of method and applied in terms of objective. The data collection tool was a questionnaire. The results of the hypothesis test showed that there is a significant relationship between the variable of human resources management and its components and the quality of professional ethics, but there was not a significant relationship between the social status variable and the quality of professional ethics.

Sabir Khan and Rashid (2014) conducted a study entitled "investigating the relationship between human resource management practices and project success with regard to the moderating role of work ethics". The present study is a descriptive and applied and the data collection tool is a questionnaire. The results of their research showed that all four components of human resource management have a positive and significant relationship with the project success and employees' development and training have the greatest impact on the success of the project. They also found that work ethics played role in this relationship and there is a significant relationship between human resource management practices and the success of the project with regarding the moderating role of work ethics.

Hussey (2014) conducted a research entitled "the effect of work ethics on labor market success". His research was applied and its method was descriptive. He collected the required data using a questionnaire. 
The results of the research hypotheses test showed that work ethics and its components (interest in work, perseverance in work, human relations at workplace, and participation in work) have a positive effect on business success and market success.

\section{Methodology}

This descriptive research is survey and causal type of study. The population of study included all 2500 staff in the city of Shiraz. Based on Morgan table, 333 of them were selected as sample of study and to ensure the return of the questionnaires, 350 subjects were selected using stratified random sampling method. In this study, latent independent variable was human resources management, latent dependent variable was organizational success, and latent moderating variable was work ethics. In the implementation stage of the study, after presenting a preliminary description of the measuring tools and objective of test, the way to respond to the tests was explained for the participants in detail. Regarding the ethical considerations, after acquiring consent from individuals and giving them necessary information, they were ensured that information received form them will be used only in this research and it will be protected from any abuse. To measure the variables of the study, researcher-made questionnaire was used. This questionnaire contains questions measure the variables of study. It has five-point Likert scale. To confirm its validity, a copy of it was provided for professors. Then, some of the questions that were unintelligible, ambiguous or unrelated to the subject, scope and location of the population were removed and some questions and items were revised to be clear. Cronbach's alpha was used to determine its reliability. The results showed that the questionnaire has good reliability [Table 1].

Table 1:Cronbach's alpha value

\begin{tabular}{|l|c|c|c|}
\hline \multicolumn{1}{|c|}{ Latent variables } & Abbreviation & $\begin{array}{c}\text { Cronbach's alpha } \\
\text { coefficient } \\
\text { (Alpha>0.7) }\end{array}$ & $\begin{array}{c}\text { Composite reliability } \\
\text { coefficient } \\
\text { (CR>0.7) }\end{array}$ \\
\hline Staff selection and employment & SSE & 0.869 & 0.919 \\
\hline Staff training and development & STD & 0.841 & 0.855 \\
\hline Staff performance evaluation & SPE & 0.749 & 0.761 \\
\hline Staff service compensation system & SCS & 0.862 & 0.871 \\
\hline Organization success & PS & 0.945 & 0.958 \\
\hline Work ethics & WE & 0.955 & 0.967 \\
\hline
\end{tabular}

As the appropriate value for Cronbach's alpha and composite reliability is 0.7 and in accordance with the findings of table above, these indices have appropriate in the case of latent variables, the appropriateness and suitability of the research reliability can be confirmed. The conceptual model of the relationship etween variables of study is as follows [Figure 1]. To analyze data, structural equation modeling was used. In all analyses, $\mathrm{P} \leq 0.05$ was considered.

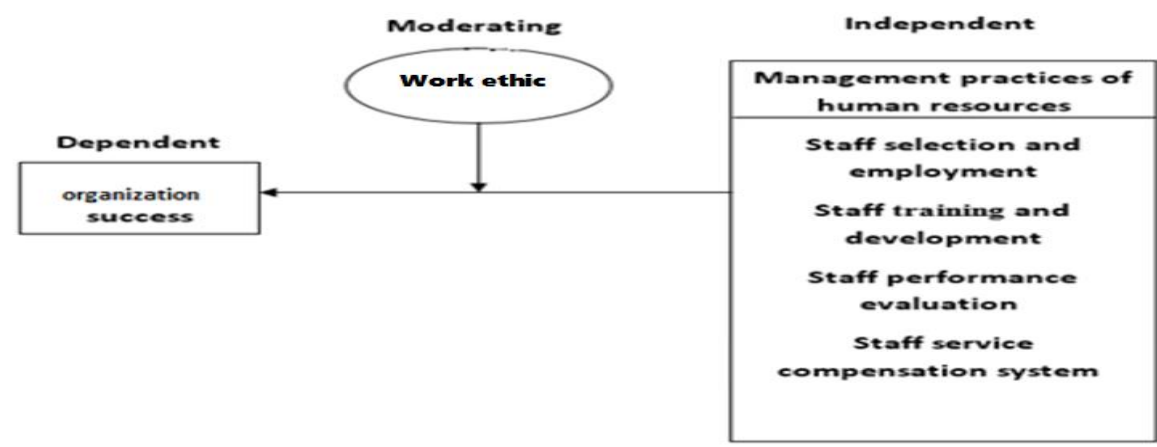

Figure 1: conceptual model of study adopted from Sabirkhan model (2014) 


\section{Rules}

[Table 2] shows the mean and standard deviation of research variables.

Table 2: Descriptive statistics of variables

\begin{tabular}{|l|c|c|c|c|c|c|c|c|}
\hline Variable & Abbreviation & Sample & Minimum & Maximum & \multicolumn{2}{|c|}{ Mean } & SD & Variance \\
\cline { 2 - 9 } & Statistic & Statistic & Statistic & Statistic & $\begin{array}{c}\text { Standard } \\
\text { error }\end{array}$ & Statistic & Statistic \\
\hline $\begin{array}{l}\text { Staff selection and } \\
\text { employment }\end{array}$ & SSE & 122 & 1.00 & 5.00 & 3.6011 & .08742 & .96556 & .932 \\
\hline $\begin{array}{l}\text { Staff training and } \\
\text { development }\end{array}$ & STD & 122 & 1.00 & 5.00 & 2.3754 & .08854 & .97796 & .956 \\
\hline $\begin{array}{l}\text { Staff performance } \\
\text { evaluation }\end{array}$ & SPE & 122 & 1.00 & 5.00 & 3.5590 & .08846 & .97707 & .955 \\
\hline $\begin{array}{l}\text { Staff service } \\
\text { compensation } \\
\text { system }\end{array}$ & SCS & 122 & 1.00 & 5.00 & 3.6295 & .07989 & .88240 & .779 \\
\hline $\begin{array}{l}\text { Organization } \\
\text { success }\end{array}$ & PS & 122 & 1.00 & 5.00 & 3.3328 & .08675 & .95817 & .918 \\
\hline
\end{tabular}

\section{Model fit Goodness of fit index}

GOF index is used to evaluate the general model fit that three values of $0.01,0.25$ and 0.36 have been introduced as weak, moderate and strong values for GOF.

This index is calculated by the following formula:

\section{$G O F=\sqrt{\overline{\text { communalities }} \times \overline{R^{2}}}$}

$\overline{\text { Communalıtıes }}$ is obtained from communality values of latent variables

Table 3: communality value and $\mathrm{R} 2$ value of research variables

\begin{tabular}{|l|c|c|c|}
\hline \multicolumn{1}{|c|}{ Latent variables } & Abbreviation & Communality & $\mathrm{R}^{2}$ \\
\hline Staff selection and employment & SSE & 0.792 & 0.000 \\
\hline Staff training and development & STD & 0.810 & 0.000 \\
\hline Staff performance evaluation & SPE & 0.832 & 0.000 \\
\hline Staff service compensation system & SCS & 0.870 & 0.000 \\
\hline Organization success & PS & 0.820 & 0.455 \\
\hline Staff selection and employment & WE & 0.880 & 0.000 \\
\hline
\end{tabular}

Table 4: results of general model fit

\begin{tabular}{|c|c|c|}
\hline GOF & $\overline{\mathrm{R} 2}$ & $\overline{\text { Communality }}$ \\
\hline 0.616 & 0.455 & 0.834 \\
\hline
\end{tabular}

In [Table 3 and 4] According to the values obtained for GOF (0.616), very appropriate of general model fit is confirmed.

First hypothesis: staff selection and employment have impact on success of project. 
Standardized coefficient (path coefficient) between two variables (staff selection and employment and organization success was obtained $\beta=0.18$ and significance coefficient (t statistic) between these two variables was obtained $t=2.998$ (more than absolute value of 1.96), suggesting that there is a significant relationship between them. Therefore, we can conclude that staff selection and employment had a significant impact on organization success.

Second hypothesis: staff training and development have impact on organization success.

Standardized coefficient (path coefficient) between two variables (staff training and development and organization success was obtained $\beta=0.545$ and significance coefficient (t statistic) between these two variables was obtained $t=10.244$ (more than absolute value of 1.96), suggesting that staff training and development had a significant impact on organization success, so second hypothesis of study is confirmed.

Third hypothesis: staff performance evaluation has impact on organization success.

Standardized coefficient (path coefficient) between two variables (staff performance evaluation and development and organization success was obtained $\beta=0.123$ and significance coefficient (t statistic) between these two variables was obtained $t=2.502$ (more than absolute value of 1.96), suggesting that this relationship is significant. Therefore, it could be concluded that staff performance evaluation had a significant impact on organization success, and the third hypothesis of study is confirmed.

Fourth hypothesis: staff service compensation system evaluation has impact on organization success.

Standardized coefficient (path coefficient) between two variables (staff service compensation system evaluation and development and organization success was obtained $\beta=-0.040$ and significance coefficient ( $\mathrm{t}$ statistic) between these two variables was obtained $\mathrm{t}=0.615$ (less than absolute value of 1.96), suggesting that this relationship is not significant. Therefore, it could be concluded that staff service compensation system had no significant impact on organization success, and the fourth hypothesis of study is not confirmed.

Fifth hypothesis: staff selection and employment have significant impact on organization success considering the moderating role of work ethics.

Significance coefficient $\mathrm{Z}$ related to variable SSE*WE was obtained 0.659 , and as it is lower than 1.96 , it suggests that at the confidence level of $95 \%$, this relationship with moderating role of work ethics cannot be confirmed. In other words, at the confidence level of $95 \%$, it could be confirmed that the variable of work ethics does not moderate the impact of staff selection and employment on the organization success. Therefore, the fifth hypothesis of study is not confirmed.

Sixth hypothesis: staff training and development have significant impact on organization success considering the moderating role of work ethics.

Significance coefficient $\mathrm{Z}$ related to variable STD*WE was obtained 2.655, and as it is higher than 1.96 , it suggests that at the confidence level of $95 \%$, this relationship with moderating role of work ethics can be confirmed. In other words, at the confidence level of $95 \%$, it could be confirmed that the variable of work ethics moderates the impact of staff training and development on the organization success. Therefore, the sixth hypothesis of study is confirmed.

Seventh hypothesis: staff performance evaluation has significant impact on organization success considering the moderating role of work ethics. 
Significance coefficient $\mathrm{Z}$ related to variable SPE*WE was obtained 0.742 , and as it is lower than 1.96 , it suggests that at the confidence level of $95 \%$, this relationship with moderating role of work ethics cannot be confirmed. In other words, at the confidence level of $95 \%$, it could be confirmed that the variable of work ethics does not moderate the impact of staff performance evaluation on the organization success. Therefore, the seventh hypothesis of study is not confirmed.

Eighth hypothesis: staff service compensation system has significant impact on organization success considering the moderating role of work ethics.

Significance coefficient $\mathrm{Z}$ related to variable SCS*WE was obtained 1.996, and as it is higher than 1.96, it suggests that at the confidence level of $95 \%$, this relationship with moderating role of work ethics can be confirmed. In other words, at the confidence level of $95 \%$, it could be confirmed that the variable of work ethics moderates the impact of staff service compensation system on the organization success. Therefore, the eighth hypothesis of study is confirmed in [Figure 2 and 3].

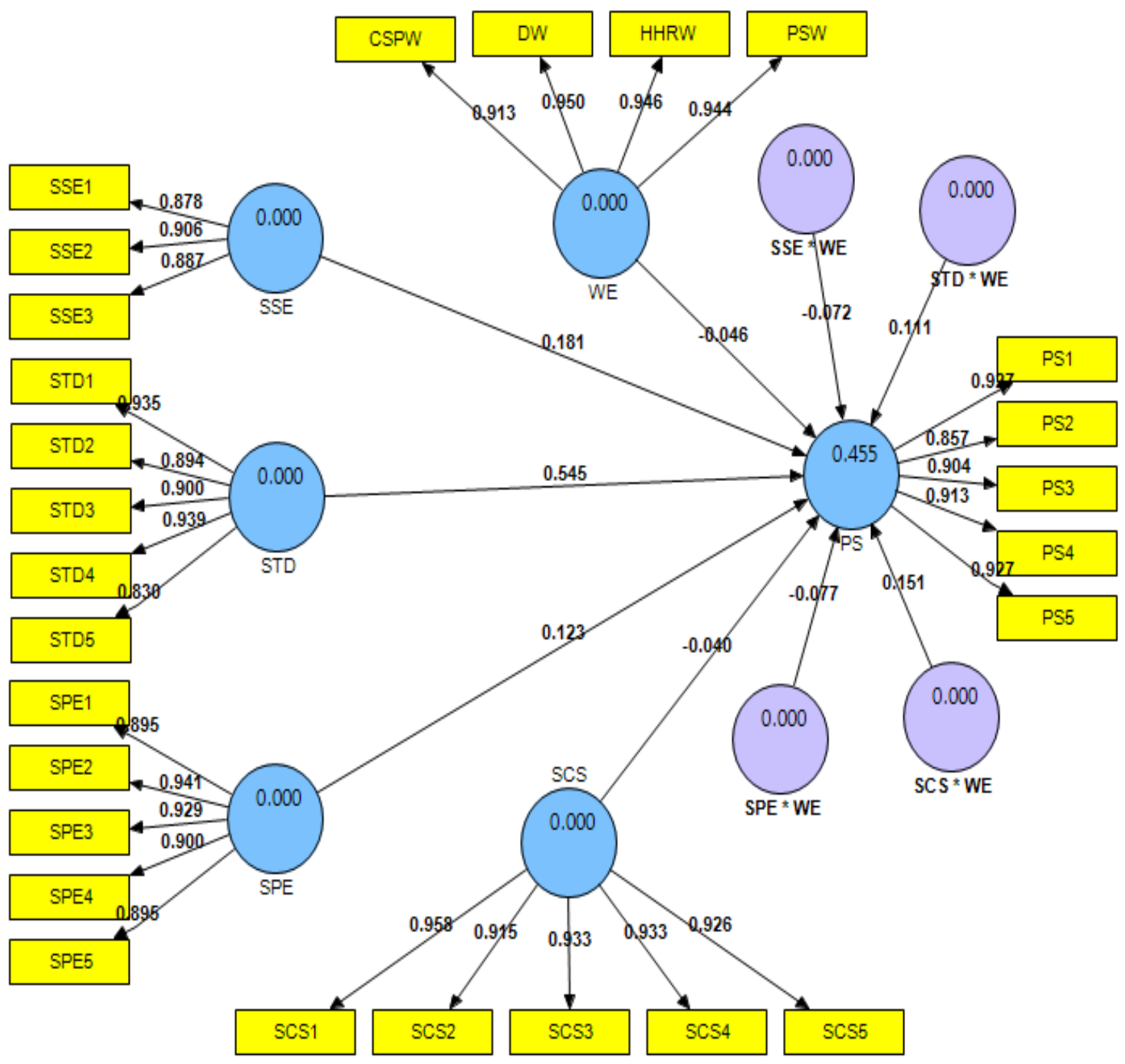

Figure 2: structural model of study along with coefficients of factor loads 


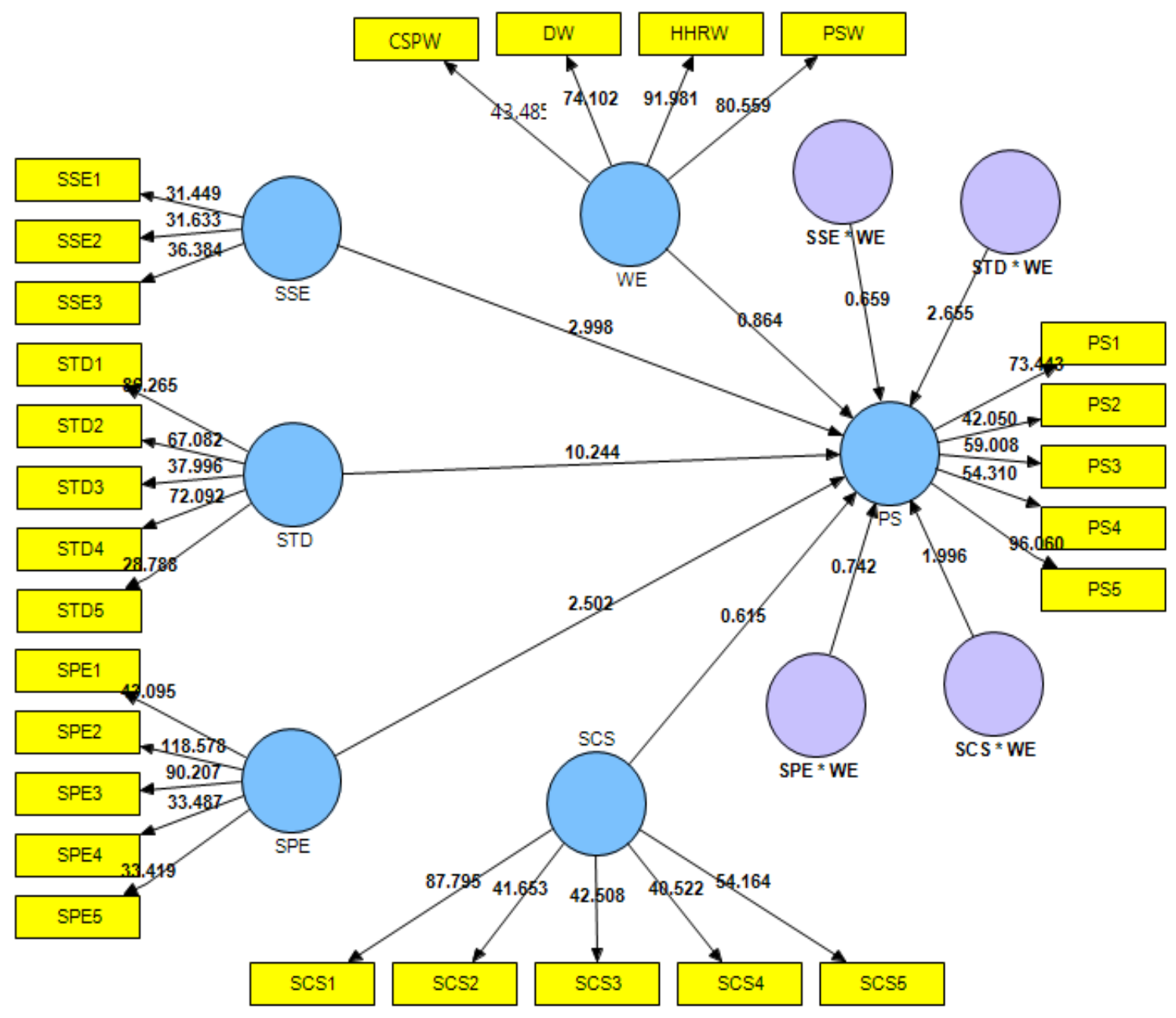

Figure 3: structural model of study along with significance coefficients

\section{Discussion and Conclusion}

The objective of this study was to investigate the impact of HRM on organizational success considering the moderating role of work ethics in public organizations of Shiraz. The results showed the staff selection and employment had significant impact on the success of the project. Staff training and development had also significant impact on success of the project. These hypotheses results are in line with results of Sabirkhan and Rashid (2014), Heumann et al (2012). Staff performance evaluation had a significant effect on the success of the project that this hypothesis result is in line with results of research conducted by Hafezi and Faezi (2014), Sabirkhan and Rashid (2014). Staff service compensation system has no significant impact on success of the project, considering the moderating role of work ethics, and staff performance evaluation has no impact on success considering the moderating role of work ethics that these results are not in line with studies conducted by the researchers. Staff training and development has significant impact on the success of the project considering the moderating role of work ethics that this result is in line with result of Sabirkhan and Rashid (2014). Hafezi and Faezi (2014) conducted a study entitled "The impact of the strategic management of human resources on the success of development projects". The results of this strategy will increase efficiency and reduce turnover, which is a revolutionary strategy in development projects .Sabirkhan and Rashid (2014) conducted research entitled "the relationship between human 
resource management practices and the success of the project with regard to the moderating role of work ethics". The results of the study showed that all four components of human resources management had a significant and positive success of the project and staff training and development had the highest impact on the success of the project. They also found that the work ethics had a role in this relationship and significant relationship was found between human resources management practices and success of the project with regard to the moderating role of work ethics. Heumann et al (2012) conducted a research in the field of the relationship between human resources management and enhancing the performance of the organization. They assessed different practices of human resources management on the performance of the organizations and concluded that new human resource management practices dramatically increase the performance of the organization. They indicated that the human resources training establishing a fair system of salaries and bonuses had the greatest share in increasing the performance of the staff.

\section{References}

Armstrong, M., \& Baron, A. (2003). The key to Improved Business Performance. London: CIPD.

Dunford, B. B., Snell, S. A., \& Wright, P. M. (2007). Human Resources and Resource-Based View of The Firm. Ithaca, Ny: Cornell University, School of Industrial and Labor Relations.

Gollan, P. (2005). High involvment management and human resource sustainability. Asia Pacific Journal of Human Resources, Vol. 43(No. 1), pp. 18-33.

Hafezi, F, Fayezi, SF(2014), The impact of strategic management of human resource on the success of development projects, International Management Conference in the 21st Century

Harpaz, I. M. (2010). The meaning of work, employment relations, and strategic human resource management in Israel. Human Resource Management Review, Vol. 20(No.3), pp. 212-223.

Rabinz, A. (2006), organizational behavior, translated by Ali Parsaeian and Seyed Mohammad Arabi, Volume III, published by the Cultural Research Bureau

Rodriguez, J., \& Ventura, J. (2003). Human resource management systems and organizational performance: an analysis of the Spanish manufacturing industry. International Journal of Human Resource Management, Vol. 14(No. 7), pp.1206-26.

Sabir Khan, Adeel, Farooq Rasheed(2014), Human resource management practices and organization success, a moderating role of Islamic Work Ethics in Pakistani project-based organizations, International Journal of Project Management xx (2014) xxx-xxx

Soleimani, M, Nasrabadi, AB (2012), The role of human resources management in enhancing ithe professional ethics of religious research centers of Qom Province, Journal of Islamic and Management Studies, 125-143 